\title{
Fabp3 Inhibits Proliferation and Promotes Apoptosis of Embryonic Myocardial Cells
}

\author{
C. Zhu $\cdot$ D. L. Hu $\cdot$ Y. Q. Liu $\cdot$ Q. J. Zhang $\cdot$ \\ F. K. Chen $\cdot$ X. Q. Kong $\cdot$ K. J. Cao • \\ J. S. Zhang $\cdot$ L. M. Qian
}

Published online: 4 February 2011

(c) The Author(s) 2011. This article is published with open access at Springerlink.com

\begin{abstract}
Fatty acid binding protein 3 (FABP3) is a member of a family of binding proteins. The protein is mainly expressed in cardiac and skeletal muscle cells, and it has been linked to fatty acid metabolism, trafficking, and signaling. Using suppression subtractive hybridization, we previously found that FABP3 is highly regulated in ventricular septal defect (VSD) patients and may play a significant role in the development of human VSD. We therefore aimed to identify the biological characteristics of the FABP3 gene in embryonic myocardial cells. On the basis of RT-PCR and western blotting analyses, we demonstrated that the expression levels of FABP3 mRNA and protein were up-regulated initially and then gradually decreased with P19 cell differentiation. MTT assays and cell cycle analysis showed that FABP3 inhibits P19 cell proliferation, and data from annexin V-FITC assays revealed that FABP3 can promote apoptosis of P19 cells. Further data from quantitative real-time RT-PCR revealed
\end{abstract}

C. Zhu, D. L. Hu contributed equally to this work.

\section{Zhu}

Department of Pediatrics, Nanjing Maternal and Child Health Hospital of Nanjing Medical University, Nanjing 210004,

People's Republic of China

D. L. Hu · Y. Q. Liu - Q. J. Zhang · F. K. Chen

X. Q. Kong · K. J. Cao · L. M. Qian ( $\bowtie)$

Department of Cardiology, The First Affiliated Hospital

of Nanjing Medical University, Nanjing 210029,

People's Republic of China

e-mail:1mqian@njmu.cn

\section{J. S. Zhang ( $\square)$}

Department of Emergency, The First Affiliated Hospital

of Nanjing Medical University, Nanjing 210029,

People's Republic of China

e-mail: Zhangjso@sina.com lower expression levels of cardiac muscle-specific molecular markers (cTnT, alpha-MHC, GATA4, and MEF2c) in FABP3-overexpressing cell lines than in the control cells during differentiation. Our results demonstrate that FABP3 may be involved in the differentiation of cardiac myocytes.

Keywords CHD - LYRMI - P19 cells ·

Heart development

\section{Introduction}

Congenital heart disease (CHD) is the most common type of birth defect, the incidence of which has been reported to vary approximately from $4 / 1,000$ to $50 / 1,000$ live births $[1,2]$. Ventricular septal defect (VSD) is the most common form of $\mathrm{CHD}$ and among the most frequently encountered of congenital abnormalities [3]. As a multifactorial complex disease, environmental, and genetic factors have been identified that could play important roles in the formation of an interventricular septum. Currently, rapid progress in molecular markers and developmental biology is being made with regard to CHD. However, to date, very few VSD-causing genes have been identified. Thus, the identification and characterization of novel genes and proteins associated with VSD remains an important issue.

Fatty acid-binding protein 3 (FABP3) is a low molecular weight protein with distinct tissue distribution, which may play an important role in fatty acid transport, cell growth, cellular signaling, and gene transcription $[4,5]$. FABP 3 is upregulated during terminal differentiation of mouse cardiomyocytes [6]. In previous studies using suppression subtractive hybridization, we identified genes that were differentially expressed in VSD and normal ventricular septum myocardium [7]. We found that FABP3 is more 
highly expressed in VSD myocardium than in normal myocardium. Therefore, we selected this protein for further analysis. The P19 mouse teratocarcinoma cell line is one of the suitable models for cardiac differentiation at the molecular and functional levels [8]. Therefore, we selected the P19 cell line to investigate the effects of FABP3 on cardiac differentiation, proliferation, and apoptosis, and determined the expression level of cardiac troponin I $(\mathrm{cTnT})$ gene protein to confirm the differentiation of cardiac precursors into mature cardiomyocytes [9]. In this study, we initially examined the changes in FABP3 mRNA and protein expression during the differentiation of P19 cells to cardiac myocytes. We then went on to examine the effect of FABP3 on cell differentiation, proliferation, and apoptosis by establishing a stable P19 cell line overexpressing FABP3, and found that the expression levels of FABP3 mRNA and protein were up-regulated initially and then gradually decreased with P19 cell differentiation. Overexpression of FABP3 in P19 cells inhibits proliferation and promotes apoptosis of these cells. P19 cell lines overexpressing FABP3 also showed lower expression levels of cardiac muscle-specific molecular markers when compared with the control cells. These results suggest that the $F A B P 3$ gene may be involved in the differentiation of cardiac myocytes.

\section{Materials and Methods}

\section{Cell Culture}

The P19 cells used in this study were obtained from the American Type Culture Collection (ATCC, Manassas, VA, USA). The cells were cultured in $\alpha$-modified Eagle's medium ( $\alpha$-MEM; Gibco BRL, Grand Island, NY, USA) supplemented with $10 \%$ fetal bovine serum (FBS; Gibco BRL), $100 \mathrm{U} / \mathrm{ml}$ penicillin, and $100 \mu \mathrm{g} / \mathrm{ml}$ streptomycin at $37^{\circ} \mathrm{C}$ in $5 \% \mathrm{CO}_{2}$. In order to induce cardiac differentiation, embryoid body (EB) formation was induced by plating $1 \times 10^{6}$ P19 cells in $10-\mathrm{cm}$ bacterial dishes containing $15 \mathrm{ml}$ of $\alpha$-MEM supplemented with $1 \%$ DMSO (Sigma, St. Louis, MO, USA), $10 \%$ FBS, $100 \mathrm{U} / \mathrm{ml}$ penicillin, and $100 \mu \mathrm{g} / \mathrm{ml}$ streptomycin for $96 \mathrm{~h}$. The resulting EBs were transferred to $6-\mathrm{cm}$ bacterial dishes, and cultured in $\alpha$-MEM containing 10\% FBS for an additional 4 or 6 days. Morphological changes in the P19 cells were examined and photographed under an inverted microscope (Nikon, Japan).

Establishment of a Stable Cell Line Overexpressing Fabp3

The coding sequence of FABP3 was subcloned into the EcoRI/XhoI sites of a pcDNA3.1/myc-His B expression vector, using the oligonucleotides $5^{\prime}$-AGCTGAATTCTGC AATGGCGGACGCCTTTGTC- $3^{\prime}$ and $5^{\prime}$-AGCTCTCG AGCGCGCCT CCT TCT CATAAG- $3^{\prime}$ to generate a plasmid expressing a FABP3-6 $\times$ His fusion protein. Expression vectors carrying the FABP 3 coding sequence or empty vectors were transfected into P19 cells. Two days after transfecton, neomycin (G418; Roche, Basel, Switzerland) was added to the medium $(600 \mu \mathrm{g} / \mathrm{ml})$ to select transfected cells. After 2 weeks, individual colonies were isolated, propagated, and the expression of the FABP3- $6 \times$ His fusion protein was confirmed by western blotting using an anti- $6 \times$ His antibody (Clontech, Mountain View, CA). The colonies expressing the highest levels of FABP3 were selected for study.

\section{MTT Assay}

To analyze the growth of stably transfected P19 cells, the cells $\left(2.5 \times 10^{2} /\right.$ well $)$ were seeded in 96-well plates and cultured in $\alpha$-MEM supplemented with $10 \%$ FBS. Cell growth was monitored for 5 days using a Cell Proliferation MTT Kit (Roche Diagnostics, GmBH, Mannheim, Germany) as recommended by the manufacturer. The absorbance at 550 and $690 \mathrm{~nm}$ was recorded using an ELISA reader, and the OD was calculated as the difference between absorbances at the two wavelengths.

\section{Cell Cycle Assay}

Cells were incubated at a density of $2 \times 10^{6}$ cells/ $750 \mathrm{~mm}^{2}$ in $\alpha$-MEM containing $10 \%$ FBS, then washed with PBS and starved in serum-free $\alpha$-MEM for $24 \mathrm{~h}$ to synchronize. The cell cycle was initiated by replacement of the starvation medium with full medium ( $\alpha$-MEM containing 10\% FBS) for various times $(0,12,18$, and $24 \mathrm{~h})$ after serum deprivation. Cultured cells were harvested using trypsin/EDTA and washed twice with PBS. Aliquots of $2 \times 10^{6}$ cells were centrifuged, fixed in $70 \%$ ethanol, and stained with $500 \mu \mathrm{l}$ of propidium iodide (PI) solution $(100 \mu \mathrm{g} / \mathrm{ml}$ RNase and $50 \mu \mathrm{g} / \mathrm{ml}$ PI in $1 \times$ PBS). Labeled cells were analyzed using a BD FACScan and the data were analyzed using CellQuest software.

\section{Apoptosis Assay}

Cells were cultured in FBS-free $\alpha$-MEM for $24 \mathrm{~h}$ to induce apoptosis. Cells were then harvested using trypsin/EDTA at 0 and $24 \mathrm{~h}$ after replacing the FBS-free $\alpha$-MEM with full medium ( $\alpha$-MEM containing 10\% FBS), washed with PBS, resuspended in $1 \mathrm{ml}$ binding buffer, and stained with $10 \mu \mathrm{l}$ lnnexin V-FITC and $10 \mu \mathrm{l}$ PI at room temperature for 5 min (Biovision, CA, USA). The fluorescence of FITC and PI was analyzed by flow cytometry. 
Western Blotting

Cultured cells were directly transferred to tubes containing lysis buffer $(50 \mathrm{mmol} / \mathrm{l}$ Tris-HCl, $1 \%$ Triton $\mathrm{X}-100,0.2 \%$ sodium deoxycholate, $0.2 \% \mathrm{SDS}$, and $1 \mathrm{mmol} / \mathrm{l}$ EDTA at $\mathrm{pH}$ 7.4) and vortexed briefly. The lysate supernatant was collected after centrifugation at $15,200 \mathrm{~g}$ for $15 \mathrm{~min}$ at $4^{\circ} \mathrm{C}$. Protein concentration determinations using a protein assay reagent kit, and western blotting using a monoclonal rabbit anti-cTnT antibody (CHEMICON, USA), anti-FABP3 antibody (Genetex, USA), and a monoclonal rabbit antiGAPDH antibody (Proteintech Group, Inc., China), were performed as described previously [10].

\section{RT-PCR}

Total RNA was isolated from cultured P19 cells using the TRIzol method (Invitrogen, Carlsbad, CA, USA). cDNA was synthesized from $1 \mu \mathrm{g}$ of total RNA using an AMV Reverse Transcriptase Kit (Promega A3500; Promega, Madison, WI, USA). An aliquot (10\%) of the resulting cDNA was amplified with the primers listed in Table 1 . The number of cycles and reaction temperatures used in the PCR assay were optimized to provide a linear relationship between the amount of input template and the amount of PCR product.

Establishment of a Stable Cell Line Overexpressing Fabp3

For overexpression studies, FABP3-pcDNA3.1/myc-His $\mathrm{B}(+)$ was constructed by inserting the PCR amplified ORF of FABP3 into EcoRI and XhoI sites of the vector. The primers used to clone the open-reading frame of FABP3 cDNA were 5'-AGCTGAATTCTGCAATGGCGGACGC CTTTGTC- $3^{\prime}$ and $5^{\prime}$-AGCTCTCGAGCGCGCCT CCT TCT CATAAG- $3^{\prime}$. Expression vectors carrying the FABP3 coding sequence, or empty vectors, were transfected into P19 cells. At $48 \mathrm{~h}$ after transfection, neomycin (G418, Roche) was added to the medium $(600 \mu \mathrm{g} / \mathrm{ml})$ to select transfected cells. After 2 weeks, individual colonies were isolated, propagated, and the expression of the FABP3$6 \times$ His fusion protein was confirmed by western blot. The anti- $6 \times$ His antibody used was from Clontech. Colonies expressing the highest levels of FABP3 were selected for cell studies.

Table 1 Primer sequences and annealing temperature used in PCR
Quantitative Real-Time RT-PCR

Total RNA was extracted from P19 cells using TRIzol reagent (Invitrogen). cDNA was then synthesized from $1 \mu \mathrm{g}$ of total RNA using the AMV Reverse Transcriptase Kit (Promega). Real-time PCR was performed using the SYBR Green method in an Applied Biosystems 7300 Sequence Detection System (ABI 7300 SDS; Foster City, CA, USA) following the manufacturer's protocols. The PCR conditions included a denaturation step $\left(95^{\circ} \mathrm{C}\right.$ for $10 \mathrm{~min}$ ), and amplification and quantification were repeated 40 times $\left(95^{\circ} \mathrm{C}\right.$ for $15 \mathrm{~s}, 60^{\circ} \mathrm{C}$ for $\left.1 \mathrm{~min}\right)$. The measurement of gene expression was performed in triplicate. The relative gene expression levels were quantified based on the $\mathrm{Ct}$, and normalized to the reference gene $G A P D H$. The sequences of the primers used are shown in Table 2. Each sample was measured in duplicate, and the gene expression levels were calculated by the $2^{-\Delta \Delta C T}$ method as described previously [11].

\section{Statistical Analysis}

Each experiment was performed at least three times. All values are presented as the mean \pm SD. Statistical analysis was performed using one-way ANOVA and $t$ - or $t^{\prime}$ tests with a correction for multiple comparisons, as appropriate. Statistical significance was assumed when $P<0.05$.

Table 2 Primer sequences and product size used in quantitative realtime RT-PCR

\begin{tabular}{lll}
\hline Gene & Sequences $\left(5^{\prime}-3^{\prime}\right)$ & $\begin{array}{l}\text { Product } \\
\text { size }(\mathrm{bp})\end{array}$ \\
\hline cTnT & $\begin{array}{l}\text { F: CAGAGGAGGCCAACGTAGAAG } \\
\text { R: CTCCATCGGGGATCTTGGGT }\end{array}$ & 138 \\
& F: GCCCAGTACCTCCGAAAGTC & 110 \\
& R: GCCTTAACATACTCCTCCTTGTC & \\
GATA4 & F: CCCTACCCAGCCTACATGG & 139 \\
& R: ACATATCGAGATTGGGGTGTCT & \\
MEF2c & F: TGTCCAGCCATAACAGTTTGG & 177 \\
& R: CCTTGTGAACATGAAGTCCTCTT & \\
\hline
\end{tabular}

\begin{tabular}{lllll}
\hline Gene & Sequences $\left(5^{\prime}-3^{\prime}\right)$ & Product size $(\mathrm{bp})$ & $\begin{array}{l}\text { Annealing } \\
\text { temperature }\left({ }^{\circ} \mathrm{C}\right)\end{array}$ & Cycles \\
\hline FABP3 & $\begin{array}{l}\text { F: ACCAAGCCTACTACCATCATC } \\
\text { R: GTCACGACCTCCTTCTCAT }\end{array}$ & 285 & 54.7 & 24 \\
GAPDH & $\begin{array}{l}\text { F: ACCACAGTCCATGCCATCAC } \\
\text { R: TCCACCACCCTGTTGCTGTA }\end{array}$ & 450 & 60.7 & 20 \\
\hline
\end{tabular}




\section{Results}

\section{Appraisal of Cell Differentiation}

To investigate the differentiation of P19 cells into mature cardiomyocytes, we used western blotting to identify the expression of cTnT protein after the beating of cells was observed. In Fig. 1, we show the increase in cTnT expression.

The Changes in Fabp3 Mrna and Protein Expression During Differentiation

When P19 cells were induced to differentiate to cardiac myocytes, the expression level of FABP3 mRNA had a tendency to down-regulate gradually from $\mathrm{d} 0$ to $\mathrm{d} 6$, and there were significant differences between $\mathrm{d} 0$ and $\mathrm{d} 2-4$ and between d2-4 and d5-6 (Fig. 2a). However, there was no significant difference in the expression level of FABP3 protein between $\mathrm{d} 0$ and $\mathrm{d} 2-4$, even though the expression pattern of FABP3 protein during the differentiation of P19 cells was the same as that of FABP3 mRNA, with the lowest expression at $\mathrm{d} 4$ of differentiation. FABP3 mRNA expression had a tendency to up-regulate after d5 gradually. The western blot results were consistent with those of RT-PCR (Fig. 2b).

\section{Establishment of Stable Overexpressing FABP3 P19 Cells}

Stable FABP3-overexpressing P19 cells and the emptyvector controls were established and maintained in a-MEM
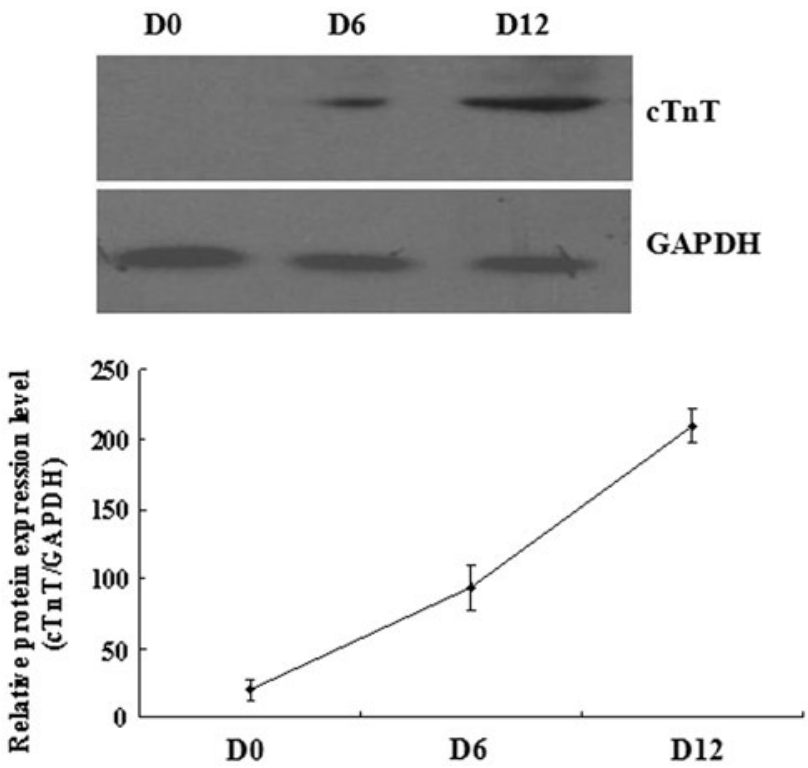

Fig. 1 Appraisal of cell differentiation. Western blot analysis of cTnT protein during differentiation
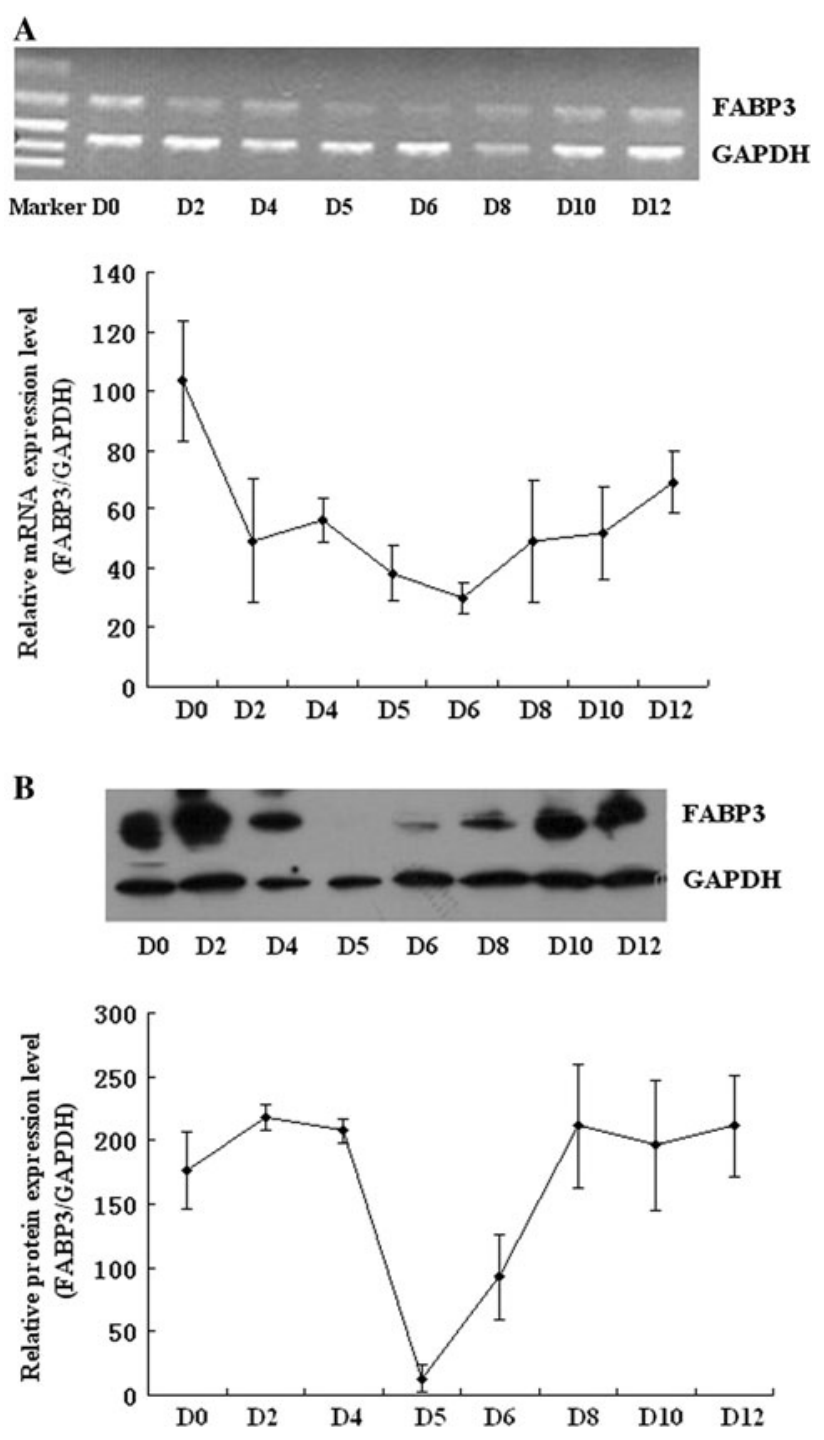

Fig. 2 The changes in FABP3 mRNA expression during differentiation. a The changes in FABP3 mRNA expression during differentiation were confirmed by RT-PCR. b Western blotting shows the changes in FABP3 protein expression during differentiation. The results represent the mean $\pm \mathrm{SD}$ of six experiments

containing $250 \mu \mathrm{g} / \mathrm{ml} \mathrm{G} 418$. FABP3 protein expression was verified by western blot analysis (Fig. 3).

\section{Effect of FABP3 on Cell Differentiation}

In Fig. 4a, we show that there was no significant difference in the morphology of P19 cell lines overexpressing the $F A B P 3$ gene on days 0,4 , and 12 of differentiation and the control cells. However, when we used quantitative realtime RT PCR to analyze the expression of cardiac musclespecific molecular markers (cTnT, alpha-MHC, GATA4, MEF2c) in these cells during differentiation, we found that cell lines overexpressing FABP3 showed lower expression 


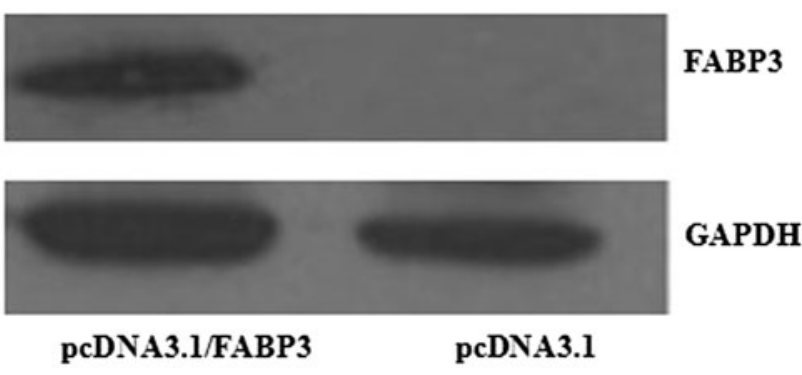

Fig. 3 Establishment of stable overexpressing FABP3 P19 cells. Western blot analysis of FABP3 expression. P19 cells were transfected with pcDNA3.1Myc/HisB-FABP3 or empty vector. Total cellular protein was extracted from the cells and subjected to western blot analysis. The experiment was repeated three times with similar results

levels of these marker genes when compared with the control cells at days 6, 8, and 12 (Fig. 4b).

\section{Effect of FABP3 on Cell Proliferation}

Cell growth was analyzed by MTT assay every day for a period of 5 days. P19 cells stably transfected with pcDNA3.1Myc/HisB vector served as controls. As shown in Fig. 5a, control cells had a considerably higher proliferation rate compared with cells with ectopic expression of FABP3 $(* P<0.05$, ** $P<0.001)$. Cell cycle analysis was used to further evaluate the effect of FABP3 on cell proliferation., Data from flow cytometry assays shows that, more than $60 \%$ cells of both cell lines stayed in G1 phase after starvation of serum for $48 \mathrm{~h}$. Compared with the control cells, overexpression of FABP3 prevents P19 cells entering into the $\mathrm{S}$-phase from $18 \mathrm{~h}$ after serum stimulation (* $P<0.05)$ (Fig. 5b).

\section{Effect of FABP3 on Cell Apoptosis}

Annexin V-FITC binds to phosphatidylserine and can be used to detect the early stages of apoptosis [12]. To study the effect of FABP3 on cell apoptosis, cells were cultured in FBS-free $\alpha$-MEM for $24 \mathrm{~h}$ to induce apoptosis. Apoptotic cells were quantified by flow cytometric analysis after staining with Annexin V-FITC. This showed that FABP3 promotes P19 cell apoptosis when the cells were induced by serum deprivation $(* P<0.05)$ (Fig. 6).

\section{Discussion}

Observational epidemiological studies of CHD have demonstrated the existence of gene predispositions [13]; however, the genetic basis of the majority of CHD remains unknown. To date, only a few genes or markers as critical regulators of heart formation have been identified as being associated with CHD; these include NKX2.5 [14], Tbx5 [15], and GATA4 [16]. Nevertheless, for most CHDs, the basic pathogenetic mechanism of VSD is still unclear.

Previous studies have shown that FABP3 is expressed in mouse neonatal hearts and its expression is up-regulated in these hearts during cardiomyocyte terminal differentiation [6]. Recently, Seino et al. [17] suggested that FABP3 may be used as a biomarker for acute coronary syndrome. However, our subtractive hybridization experiments were performed on post-natal hearts, we found that FABP3 is highly regulated in VSD patients compared with normal controls [7]. This result suggests that FABP3 plays a role in human VSD.

In this study, using RT-PCR and western blotting, we found that the expression levels of FABP3 mRNA and protein were up-regulated initially and then gradually decreased with P19 cell differentiation. However, statistical analysis of the data showed that although FABP3 mRNA expression was significantly different in P19 cell suspensions during the induction phase $(\mathrm{d} 0-\mathrm{d} 4)$, there was no significant difference in protein expression. The reason for the difference in FABP3 mRNA and protein expressions is not clear. A similar phenomenon was observed when Wang et al. [18] used in situ hybridization to detect B-FABP mRNA expression levels and immunohistochemical techniques to analyze protein expression levels in undifferentiated breast cancer cells. They considered the possibility that the FABP mRNA is not translated into protein. Since FABP3 and B-FABP genes belong to the same family and are highly homologous [19], we believe that differences in the expression patterns of FABP3 mRNA and protein at $\mathrm{d} 0-\mathrm{d} 4$ may be because some transcripts in the P19 cells remain untranslated at the d0 stage. Further work is required to assess this possibility. FABP3 mRNA and protein expression levels decreased gradually when P19 cells were inducted in suspension (after d0) to the stages of adherent culture induction (after d4-5), and then the gene expression gradually increased with the differentiation of P19 cells into mature cardiomyocytes. Therefore, we consider that the FABP3 gene may inhibit P19 cell differentiation into cardiac cells in the early stages of cell differentiation. On the basis of our previous studies showing that FABP3 is abundantly expressed in VSD myocardium, we demonstrated that the FABP3 gene may inhibit the differentiation of cardiac cells.

CHD is closely related to the differentiation, proliferation, and apoptosis of myocardial cells [20, 21]. Therefore, we investigated the effects of FABP3 on P19 cell differentiation, proliferation, and apoptosis by establishing a stably transfected P19 cell line overexpressing FABP3. First, the MTT assay showed that P19 cells overexpressing FABP3 grew slower than control cells, and cell cycle analysis by flow cytometry showed a remarkable decrease 
Fig. 4 Effect of FABP3 on cell differentiation. a There was no significant difference in the morphology of P19 cell lines overexpressing the $F A B P 3$ gene on days 0,4 , and 12 of differentiation and the control cells. b Expression of cardiac muscle-specific molecular markers (cTnT, alpha-MHC, GATA4, and MEF2c) was analyzed by quantitative realtime RT-PCR at various time points during the stimulation of differentiation (days 6, 8, and 12). The results represent the mean \pm SD of six experiments $(* P<0.05, * * P<0.001)$
A

FABP3

D0
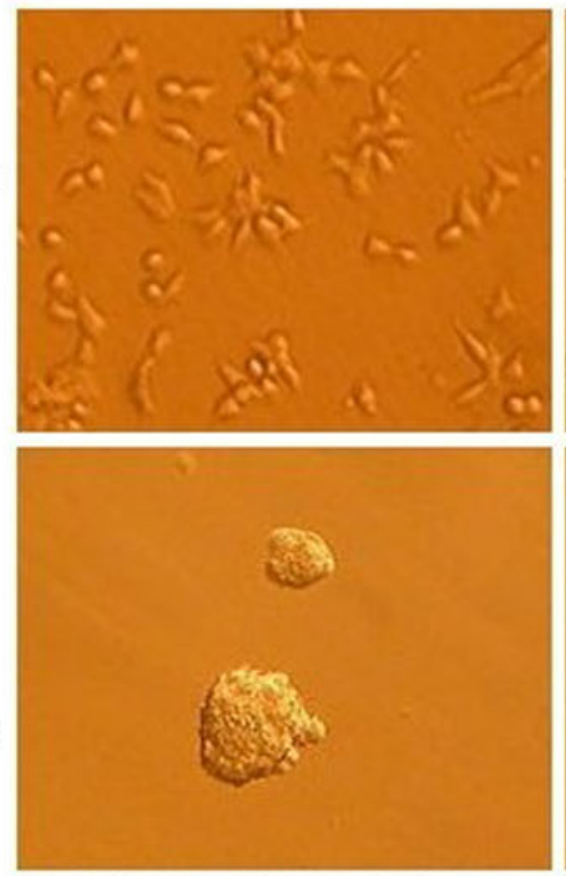

D4

D12

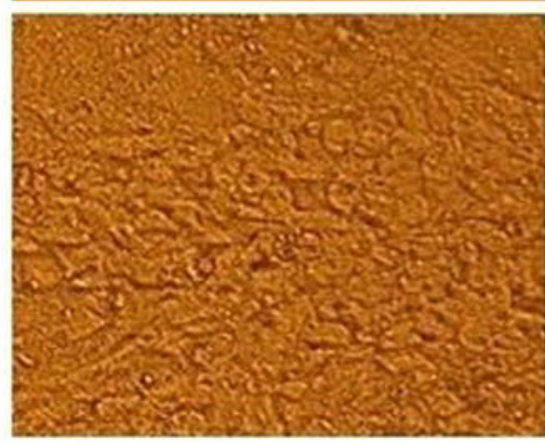

B
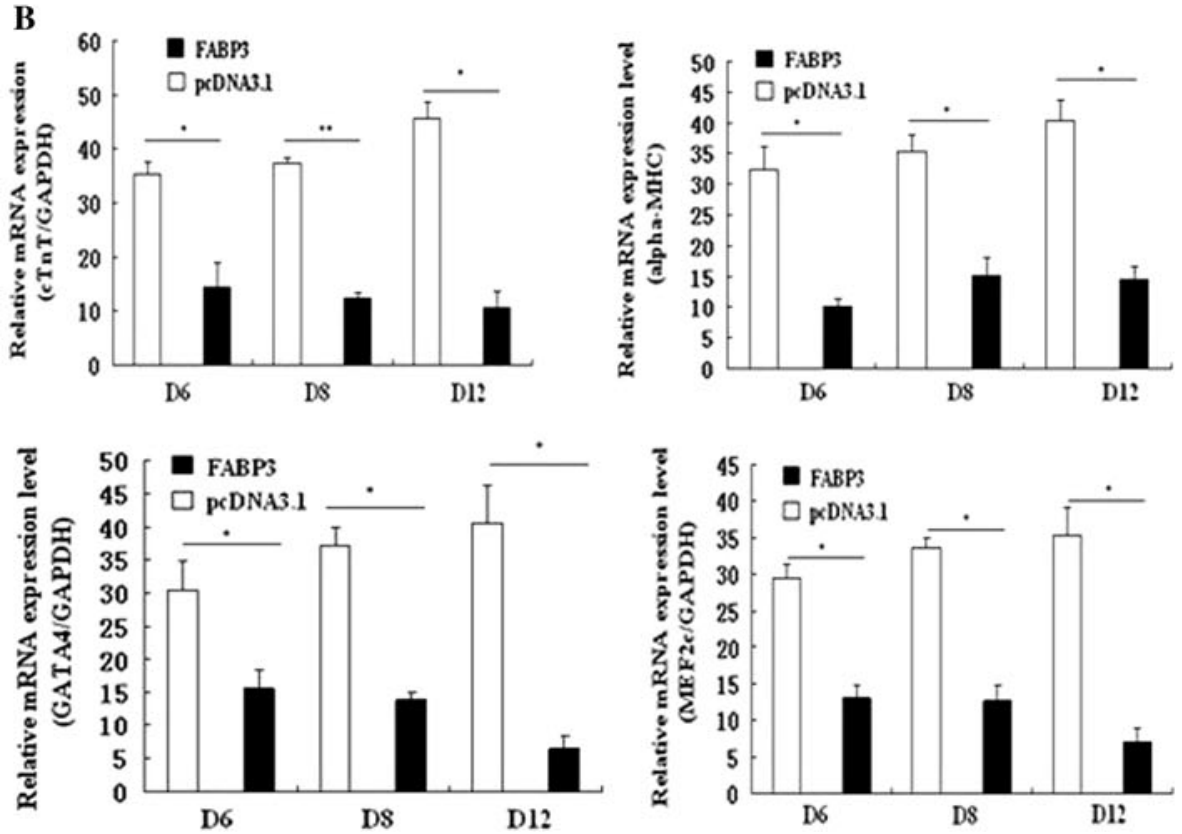

pcDNA3.1
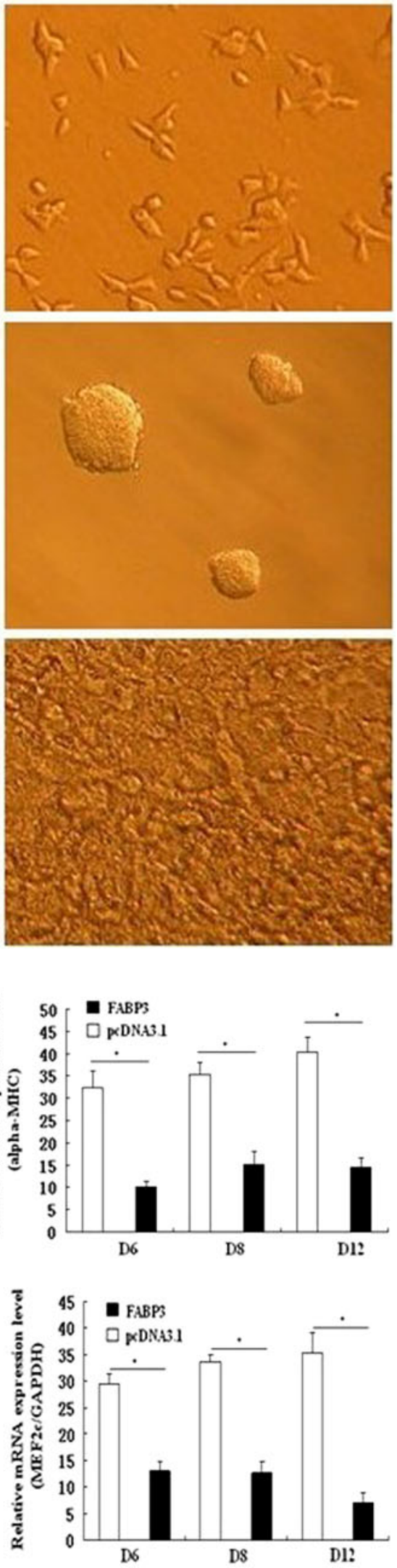

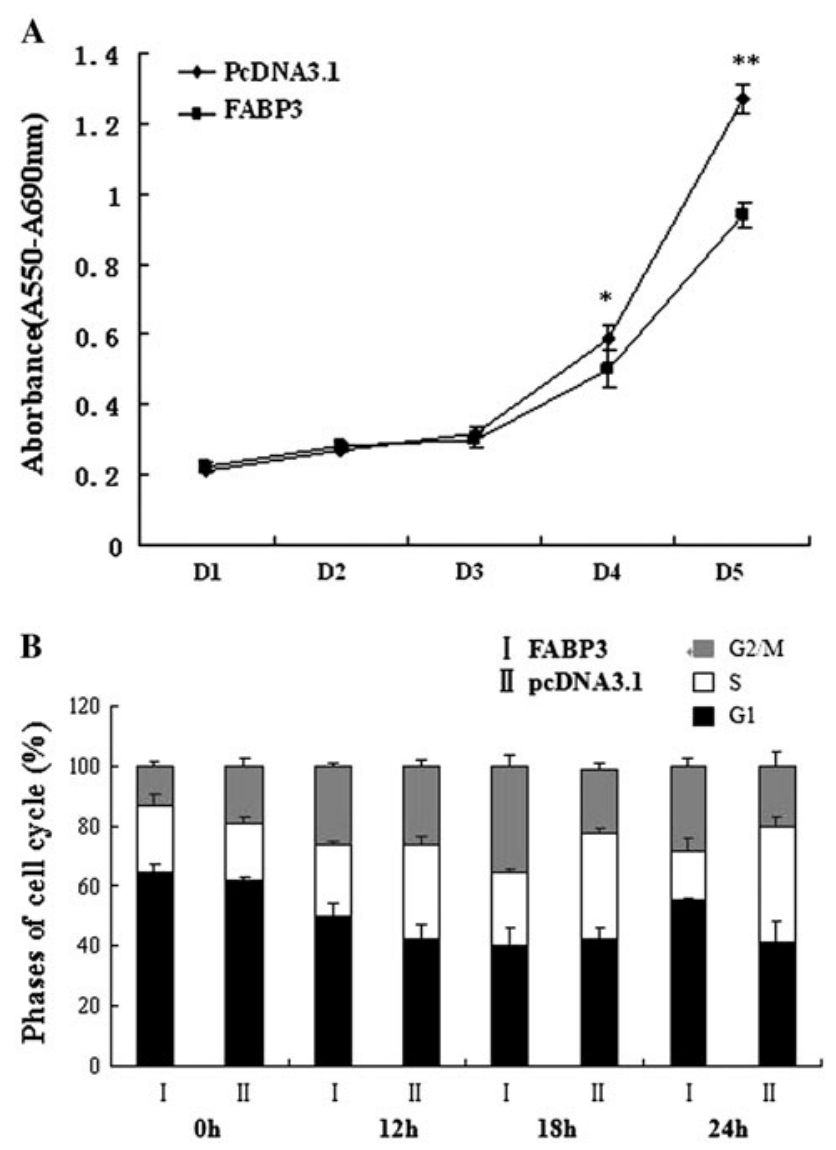

Fig. 5 Effect of FABP3 on cell proliferation. a The effects of FABP3 on cell proliferation were detected by MTT assays. b Cell cycle profile of FABP3 transfectants. The results represent the mean $\pm \mathrm{SD}$ of six experiments $(* P<0.05, * * P<0.001)$

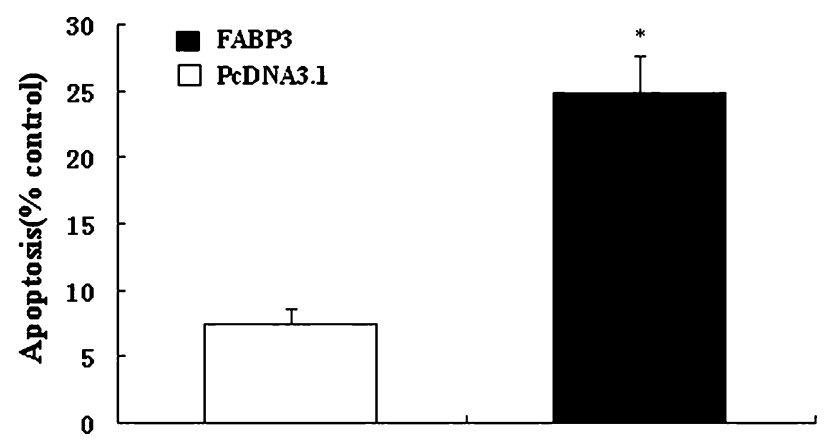

Fig. 6 Effect of FABP3 on cell apoptosis. Apoptosis was assayed by the binding of annexin V-FITC. FABP3 can promote apoptosis induced by serum deprivation in P19 cells. The results represent the mean $\pm \mathrm{SD}$ of six experiments $(* P<0.05)$

in the percentage of cells entering the S-phase. Second, annexin V-FITC analysis indicated that FABP3 can promote apoptosis induced by serum deprivation. These data showed that FABP3 inhibits proliferation and promotes apoptosis of embryonic myocardial cells. Furthermore, we also investigated the expression of cardiac muscle-specific molecular markers (cTnT, alpha-MHC, GATA4, and MEF2c) by quantitative real-time RT-PCR in cell lines overexpressing FABP3 during differentiation. The results showed that the expression levels of these marker genes were significantly lower in the cell lines overexpressing FABP3 than in control cells at days 6,8 , and 12 . We therefore consider that FABP3 may be able to significantly affect the differentiation of cardiac precursors into mature cardiomyocytes, and show inhibitory effects.

In summary, we have characterized several features of the FABP3 gene, which may play an important role in the differentiation of cardiac myocytes. Further studies using either knockdown or knockout cells with attenuated FABP3 expression, which may provide insights into the pathogenesis of CHD, are required.

Acknowledgment This work was supported by a grant from the National Natural Science Foundation of China (No. 81070138) and National Natural Science Foundation of Jiangsu Province of China (No. BK2010028).

Open Access This article is distributed under the terms of the Creative Commons Attribution Noncommercial License which permits any noncommercial use, distribution, and reproduction in any medium, provided the original author(s) and source are credited.

\section{References}

1. Hoffman, J. I., \& Kaplan, S. (2002). The incidence of congenital heart disease. Journal of the American College of Cardiology, 39, 1890-1900.

2. Garg, V. (2006). Insights into the genetic basis of congenital heart disease. Cellular and Molecular Life Sciences, 63, 1141-1148.

3. Sands, A. J., Casey, F. A., Craig, B. G., Dornan, J. C., Rogers, J., \& Mulholland, H. C. (1999). Incidence and risk factors for ventricular septal defect in "low risk" neonates. Archives of Disease in Childhood. Fetal and Neonatal Edition, 81, F61-F63.

4. Zimmerman, A. W., \& Veerkamp, J. H. (2002). New insights into the structure and function of fatty acid-binding proteins. Cellular and Molecular Life Sciences, 59, 1096-1116.

5. Qian, Q., Kuo, L., Yu, Y. T., \& Rottman, J. N. (1999). A concise promoter region of the heart fatty acid-binding protein gene dictates tissue-appropriate expression. Circulation Research, 84, 276-289.

6. Tang, M. K., Kindler, P. M., Cai, D. Q., Chow, P. H., Li, M., \& Lee, K. K. (2004). Heart-type fatty acid binding proteins are upregulated during terminal differentiation of mouse cardiomyocytes, as revealed by proteomic analysis. Cell and Tissue Research, 316, 339-347.

7. Zhang, H., Zhou, L., Yang, R., Sheng, Y., Sun, W., Kong, X., et al. (2006). Identification of differentially expressed genes in human heart with ventricular septal defect using suppression subtractive hybridization. Biochemical and Biophysical Research Communications, 342, 135-144.

8. van der Heyden, M. A., van Kempen, M. J., Tsuji, Y., Rook, M. B., Jongsma, H. J., \& Opthof, T. (2003). P19 embryonal carcinoma cells: a suitable model system for cardiac electrophysiological differentiation at the molecular and functional level. Cardiovascular Research, 58, 410-422. 
9. Choi, S. C., Yoon, J., Shim, W. J., Ro, Y. M., \& Lim, D. S. (2004). 5-Azacytidine induces cardiac differentiation of P19 embryonic stem cells. Experimental Molecular Medicine, 36, 515-523.

10. Kaczocha, M., Glaser, S. T., \& Deutsch, D. G. (2009). Identification of intracellular carriers for the endocannabinoid anandamide. Proceedings of the National Academy of Sciences of United States of America, 106, 6375-6380.

11. Livak, K. J., \& Schmittgen, T. D. (2001). Analysis of relative gene expression data using real-time quantitative PCR and the $2^{-\mathrm{DCg}}$ method. Methods, 25, 402-408.

12. Vermes, I., Haanen, C., Steffens-Nakken, H., \& Reutelingsperger, C. (1995). A novel assay for apoptosis. Flow cytometric detection of phosphatidylserine expression on early apoptotic cells using fluorescein labelled Annexin V. Journal of Immunological Methods, 84, 39-51.

13. Huang, J.-B., Liu, Y.-L., Sun, P.-W., Lv, X.-D., Du, M., \& Fan, X.-M. (2009). Molecular mechanisms of congenital heart disease. Cardiovascular Pathology, 19, e183-e193.

14. Lints, T. J., Parsons, L. M., Hartley, L., Lyons, I., \& Harvey, R. P. (1993). Nkx-2.5: a novel murine homeobox gene expressed in early heart progenitor cells and their myogenic descendants. Development, 119, 419-431.

15. Bruneau, B. G., Nemer, G., Schmitt, J. P., Charron, F., Robitaille, L., Caron, S., et al. (2001). A murine model of Holt-Oram syndrome defines roles of the T-box transcription factor Tbx 5 in cardiogenesis and disease. Cell, 106, 709-721.
16. Watt, A. J., Battle, M. A., Li, J., \& Duncan, S. A. (2004). GATA4 is essential for formation of the proepicardium and regulates cardiogenesis. Proceedings of the National Academy of Sciences of the United States of America, 101, 12573-12578.

17. Seino, Y., Ogawa, A., Yamashita, T., et al. (2006). Multi-biomarker approach to acute coronary syndrome. Nippon Rinsho, 64, 691-699.

18. Wang, M., Liu, Y. E., Ni, J., et al. (2000). Induction of mammary differentiation by mammary-derived growth inhibitor-related gene that interacts with an omega- 3 fatty acid on growth inhibition of breast cancer cells. Cancer Research, 60, 6482-6487.

19. Chmurzyñska, A. (2006). The multigene family of fatty acidbinding proteins (FABPs): function, structure and polymorphism. Journal of Applied Genetics, 47, 39-48.

20. Lévy, M., Raisky, O., Vouhé, P. R., Celermajer, D. S., Bonnet, D., \& Israël-Biet, D. (2007). Apoptotic deregulation of endothelial cells and intimal proliferation in pulmonary hypertension of congenital heart disease. Archives des Maladies du Coeur et des Vaisseaux, 100, 365-372.

21. Lévy, M., Maurey, C., Celermajer, D. S., Vouhé, P. R., Danel, C., Bonnet, D., et al. (2007). Impaired apoptosis of pulmonary endothelial cells is associated with intimal proliferation and irreversibility of pulmonary hypertension in congenital heart disease. Journal of the American College of Cardiology, 49, 803-810. 